\title{
Possibilities of preparation of exotic radionuclide samples at PSI for scientific investigations
}

\section{Journal Article}

\section{Author(s):}

Schumann, D.; Stowasser, T.; Dressler, R.; Ayranov, M.

Publication date:

2013

\section{Permanent link:}

https://doi.org/10.3929/ethz-b-000080809

\section{Rights / license:}

In Copyright - Non-Commercial Use Permitted

\section{Originally published in:}

Radiochimica acta 101(8), https://doi.org/10.1524/ract.2013.2058 


\title{
Possibilities of preparation of exotic radionuclide samples at PSI for scientific investigations
}

\author{
By D. Schumann ${ }^{1, *}$, T. Stowasser ${ }^{1}$, R. Dressler ${ }^{1}$ and M. Ayranov ${ }^{2}$ \\ ${ }^{1}$ Paul Scherrer Institute Villigen, 5232 Villigen PSI, Switzerland \\ 2 European Commission, DG-Energy, Luxembourg
}

(Received December 3, 2012; accepted in final form February 18, 2013)

(Published online July 15, 2013)

\section{Accelerator waste / Chemical separation / \\ Exotic radionuclides}

\begin{abstract}
Summary. The interactions of high-energy protons with matter produce a large variety of radionuclides due to the diversity of the induced nuclear reactions. Some of those isotopes are very rare, exotic, and, in many cases, difficult to produce by complementary methods. Valuable isotopes, interesting for scientific and technological applications, can be extracted from samples stemming from the surroundings or components of a proton accelerator, in particular if the load of the initial particle current is relatively high (esp. in the Megawatt range).

Since PSI operates one of the most powerful high-energy proton accelerators world-wide, this facility is best-suited for an R\&D program aimed at "harvesting" such isotopes. An initiative called ERAWAST (Exotic Radionuclides from Accelerator Waste for Science and Technology) was started in 2006 in order to identify and motivate potential users. After six years, first achievements as well as realistic future plans for front-end experiments are available.

The present contribution describes radiochemical separation techniques for selected examples, summarizes the most prominent results and gives an outlook on the upcoming experiments within the scope of the ERAWAST program.
\end{abstract}

\section{Introduction}

Isotope production is nowadays mainly based on neutron capture using high flux reactors and/or nuclear reactions using particle accelerators of a limited energy $(<100 \mathrm{MeV})$. In accelerator-based production facilities, compound nucleus reactions dominate, providing the production of the desired radionuclides and suppressing the formation of byproducts. However, not for every isotope such direct production routes are possible, or the achievable yields are very low. Those "exotic" radionuclides are therefore very rare, and their production is time-consuming and expensive. An alternative type of nuclear reaction is spallation, where, due to the high energy of the incoming particles (above $200 \mathrm{MeV}$ ), in principle all isotopes with masses below the sum of the target and projectile mass $\left(M_{\text {target }}+M_{\text {projectile }}\right)$ are formed. This approach requires highly sophisticated chem-

\footnotetext{
*Author for correspondence (E-mail: dorothea.schumann@psi.ch).
}

ical separation techniques (in some cases also including mass separation), but gives access to isotopes which are difficult to produce by other means. Unfortunately, nuclear data on these very complex reactions are still lacking in many cases, although they are becoming more and more important in several scientific and technical application fields, covering partitioning and transmutation of nuclear waste by accelerator driven systems (ADS) like MYRRHA [1], the design and construction of spallation neutron facilities like SNS [2] or ESS [3], the characterization of standard materials for Accelerator Mass Spectrometry (AMS), as well as for basic research in nuclear physics and nuclear astrophysics.

Experiments aimed at improving our knowledge on nuclear data typically require highly sophisticated measurement systems, in many cases large-scale facilities providing the necessary beams with high intensity and high quality and - last but not least - suitable sample material in the required amount and quality. Unfortunately, in many cases these materials are very rare and difficult to obtain. Therefore, some years ago, an initiative was launched at the Paul Scherrer Institute (PSI) to look for suitable sources for exotic radioactive isotopes from accelerator waste for several purposes (ERAWAST - Exotic Radionuclides from Accelerator WAste for Science and Technology). The first ERAWAST workshop was held in 2006 at PSI to identify requirements and attract potential users [4]. 30 participants from 12 countries participated and a first working program with shortand long-term objectives was established. In 2011, the second ERAWAST workshop took place at PSI, where the first results of this collaboration were presented as well as new ideas for experiments were developed [5]. The present paper gives an overview on the background, the achievements and future plans of ERAWAST. We report on the possibilities of isotope production at PSI and our capabilities for radiochemical separations. We shortly describe successful experiments which are published elsewhere and give an outlook on upcoming experiments.

\section{Sources for exotic radionuclides at PSI}

For more than 10 years, PSI has been running one of the most powerful cyclotrons world-wide with a proton energy 
of $590 \mathrm{MeV}$ and a beam current of up to $2.4 \mathrm{~mA}$. Among others, it feeds the neutron spallation source SINQ, where the remaining beam is fully stopped in a solid lead target. All accelerator components which interact with the intense proton beam like targets, collimators, construction materials, beam dumps, shielding and others are highly activated during use. Consequently, careful analytics in the case of dismantling is required from Swiss authorities in order to get reliable information on the radionuclide inventory for an intermediate or final disposal. After several of such analysis campaigns we have found that exotic isotopes, hardly to be produced by other nuclear reactions, are detectable in these components in distinct quantities, making it worth to perform a dedicated separation.

First attempts were successful, and now we own a worldwide unique repository of several valuable and rare isotopes [6].

In the following, we give an overview on the sources of rare radionuclides at PSI and show the possibilities for chemical separations as well as first successful applications of some selected isotopes.

\subsection{Targets and beam dumps}

A copper beam dump, installed at the $590 \mathrm{MeV}$ proton beam station at PSI, had been dismounted about 20 years ago. After an extended radiochemical analysis [7], the inner part of $2 \mathrm{~cm}$, where the highest activity concentration of ${ }^{26} \mathrm{Al}$, ${ }^{44} \mathrm{Ti},{ }^{53} \mathrm{Mn},{ }^{60} \mathrm{Fe},{ }^{59} \mathrm{Ni}$ and others was found, had been drilled out and is stored for further use.

The PSI operates a rotating graphite wheel as target for muon production where up to $20 \%$ of the intensity of the proton beam is consumed. These targets are highly enriched in ${ }^{10} \mathrm{Be}$, and can be chemically processed without any additional radioprotection after a cooling time of about $2 \mathrm{yr}$.

\subsection{Material from the SINQ facility}

The PSI spallation source SINQ contains solid lead as target material for neutron production. These activated lead targets contain besides the above mentioned isotopes also radionuclides with a higher atomic number like ${ }^{207} \mathrm{Bi},{ }^{182} \mathrm{Hf}$, rare earth elements (e.g. ${ }^{148} \mathrm{Gd},{ }^{146} \mathrm{Sm}$ and several Dy isotopes).

The material research program STIP (SINQ Target Irradiation Program) [8] deals with the study of materials properties evolution under high proton and neutron fluxes. Samples of different construction materials and different shapes were mounted into the SINQ target and irradiated for a period of two years. After mechanical testing, the samples are available for isotope extraction. All of them have very high specific activity. Stainless steel samples can be used for the preparation of ${ }^{44} \mathrm{Ti},{ }^{26} \mathrm{Al}$ and ${ }^{53} \mathrm{Mn}$ (see for a review [9]).

\subsection{SINQ cooling water}

Ultrapure $\mathrm{D}_{2} \mathrm{O}$ is used as neutron moderator and for cooling of the SINQ facility. The three installed cooling loops for different parts of the SINQ facility are unique sources for the separation of ${ }^{7} \mathrm{Be}$ as well as other long-lived isotopes from irradiated structure material $\left(e . g .{ }^{22} \mathrm{Na},{ }^{88} \mathrm{Y}\right)$. Details of the separation technique as well as the application in nuclear astrophysics are described elsewhere [10].

\subsection{Special irradiations}

Additionally, the SINQ facility offers the possibility to irradiate materials with up to $570 \mathrm{MeV}$ protons at special positions inside the SINQ target (like in the STIP). Due to the modular structure of the SINQ target, samples can be placed at positions corresponding to the energy of their excitation function maximum, and thus, guaranteeing optimized production rates of the desired isotope. Currently, for two kinds of materials the irradiations are already finished: $\mathrm{V}$ and $\mathrm{Ti}$ for ${ }^{44} \mathrm{Ti}$ production and $\mathrm{Bi}$ for ${ }^{205} \mathrm{~Pb}$ production.

\subsection{Irradiation with $71 \mathrm{MeV}$ protons (injector 2) and with up to $570 \mathrm{MeV}$ neutrons (PNA, NAA)}

Common isotope production facilities are also available at PSI. A dedicated beam line providing about $10 \%$ of the $71 \mathrm{MeV}$ proton beam, delivered by the injector 2 cyclotron was installed for proton induced isotope production. This facility is currently used mainly for production of shortlived isotopes for radio-pharmaceutical purposes. In addition to the neutron imaging and diffractometry setups at the SINQ neutron irradiation facilities were installed for preparative neutron activation (PNA) providing specific neutron fluxes relative to the delivered proton beam intensity of about $2.0 \times 10^{13} \mathrm{n} / \mathrm{cm}^{2} / \mathrm{s} / \mathrm{mA}$ and for neutron activation analysis (NAA) with specific neutron fluxes of about $0.4 \times 10^{13} \mathrm{n} / \mathrm{cm}^{2} \mathrm{~s} \mathrm{~mA} \mathrm{[11].} \mathrm{Due} \mathrm{to} \mathrm{the} \mathrm{different} \mathrm{proximity}$ of the irradiation tube noses to the spallation target the neutron spectra varied slightly, whereas in both cases predominantly thermal neutrons were delivered, but also neutrons with energy up to $570 \mathrm{MeV}$ are present to a minor part. This allows exploiting nuclear reactions others than the pure neutron capture. Both setups can operate in parallel using independent irradiation tubes into the volume of the moderator vessel and each is equipped with two pneumatic transport systems for samples up to $20 \mathrm{~g}$ in the case of the PNA and up to $8 \mathrm{~g}$ for the NAA. Therefore, best conditions in terms of the neutron flux and the exposition time can be chosen for irradiation of sample materials.

\subsection{Chemical isolation from other irradiated material}

The key prerequisite to investigate nuclear properties of exotic isotopes is not only the availability of a sufficient amount of them but also the preparation of samples or targets with a high chemical purity and mechanical stability. Manufacturing of such targets can be also performed with materials originating not from the ERAWAST program, but from other sources, esp. from outside the PSI. One example is the chemical purification of a ${ }^{63} \mathrm{Ni}$ sample from its decay product ${ }^{63} \mathrm{Cu}$. This target was recently successfully used in an experiment of astrophysical interest with the aim to determine neutron-capture cross sections of ${ }^{63} \mathrm{Ni}$ using the $\mathrm{n}_{-} \mathrm{TOF}$ facility [12].

\section{Results}

\section{$3.1{ }^{60}$ Fe samples for nuclear astrophysics}

The description of the galactic evolution and the understanding of the history of the universe require experiments 
to study the production and destruction rates of the elements under galactic conditions. Isotopes with relative long half-lives play an essential role in the s-process as so-called "waiting points" [13], where the usual neutron capture and beta decay cycle is competing with the possibility of additional neutron capture processes. One of these "Hotspots" in this research field is for instance ${ }^{60} \mathrm{Fe}$. To gain more knowledge in this field, the half-lives and neutron capture cross sections of these isotopes have to be measured with much higher accuracy than today [14].

${ }^{60} \mathrm{Fe}$ is one of the isotopes which can be hardly produced by means other than spallation reactions. Only in high-flux reactors double neutron capture of stable ${ }^{58} \mathrm{Fe}$ allows to overcome the short-lived radionuclide ${ }^{59} \mathrm{Fe}\left(T_{1 / 2}=44.5 \mathrm{~d}\right)$ to produce significant amounts of ${ }^{60} \mathrm{Fe}$. Unfortunately, samples produced this way contain the stable isotopes of iron in abundances several orders of magnitude higher. Therefore, such material will not contain macroscopic amounts of ${ }^{60} \mathrm{Fe}$ and is not suitable for the determination of capture cross sections, because its signal is strongly diluted and dominated by that from the other iron isotopes. The total activities, which are reachable by neutron activation, are comparable to the here discussed method, but require large sample masses and long irradiation periods and are, therefore, time-consuming and expensive.

For these reasons, the more appropriate source for producing large quantities of ${ }^{60} \mathrm{Fe}$ are materials exposed to highpower, highly-energetic particles. We used pieces of the proton-irradiated copper beam dump for these experiments. Several grams of $\mathrm{Cu}$ were dissolved in nitric acid and underwent several separation steps, like co-precipitation, liquidliquid extraction and ion exchange to obtain finally a product nearly free from all disturbing contaminants. Especially its ${ }^{60} \mathrm{Co}$ contamination had to be reduced strongly as ${ }^{60} \mathrm{Co}$ dominates the dose rate. Moreover, as ${ }^{60} \mathrm{Co}$ is also the decay product of ${ }^{60} \mathrm{Fe}$, the in-growth of ${ }^{60} \mathrm{Co}$ from ${ }^{60} \mathrm{Fe}$ decay can be used to determine the total ${ }^{60} \mathrm{Fe}$ activity. High levels of intrinsic background ${ }^{60} \mathrm{Co}$ will hamper such measurements. We were able to produce two samples with ${ }^{60} \mathrm{Fe}$ amounts of around $10^{16}$ atoms and activities less than $0.25 \mathrm{~Bq}{ }^{60} \mathrm{Co}$. They were successfully used for the two experiments described below.

\subsection{The re-determination of the half-life of ${ }^{60} \mathrm{Fe}$ [15]}

Prior to 2009, only one reliable value for the ${ }^{60} \mathrm{Fe}$ half-life existed [16], which had been obtained by determining the total ${ }^{60} \mathrm{Fe}$ activity with $\gamma$-spectrometry and the total number of ${ }^{60} \mathrm{Fe}$ atoms by accelerator mass spectrometry. The uncertainty of the half-life value given in [16] of $1.5 \times 10^{6} \mathrm{yr}$ was $30 \%$.

In our experiments for a new half-life measurement, a fraction of the produced ${ }^{60} \mathrm{Fe}$ sample was dissolved in $5 \mathrm{~mL}$ diluted $\mathrm{HCl}$ containing approximately $800 \mathrm{ng}$ of ${ }^{60} \mathrm{Fe}$. Applying Eq. (1)

$$
T_{1 / 2}=N / A \times \ln (2)
$$

the half-life value was determined from the activity and the number of ${ }^{60} \mathrm{Fe}$ atoms of that sample. The activity of ${ }^{60} \mathrm{Fe}$ was determined by measuring the ingrowths of the daughter nuclide ${ }^{60} \mathrm{Co}$ using $\gamma$-spectrometry, while the number of ${ }^{60} \mathrm{Fe}$ atoms was measured by Inductively Coupled Plasma Mass Spectrometry (ICP-MS). Using Eq. (1), we obtained a value of

$$
\begin{aligned}
& T_{1 / 2}=(2.62 \pm 0.04) \times 10^{6} \mathrm{yr} \\
& \text { (combined standard uncertainty, } k=1),
\end{aligned}
$$

being nearly twice the value of Kutschera et al. [16] and with a significantly reduced uncertainty. All details of sample preparations as well as the description of the ICP-MS measurement are given in [17]. This new half-life value has a great impact on theoretical nucleosynthesis calculations, on predictions of the abundances of isotopes in the iron region and the understanding of the involved stellar processes [18].

\subsection{First measurement of the neutron capture cross section at stellar energies [19]}

A ${ }^{60} \mathrm{Fe}$ containing iron target, fixed on a graphite backing was produced to carry out a first measurement of the neutron capture cross sections at stellar neutron energies (KIT Karlsruhe). Details of the target preparation are described in [20].

The number of ${ }^{60} \mathrm{Fe}$ atoms in the target was determined to be $4.5 \times 10^{15}$ by measuring the in-growth of ${ }^{60} \mathrm{Co}$ after a careful separation of the initial ${ }^{60} \mathrm{Co}$ and applying the newhalf-life value. The target was exposed to a neutron spectrum peaking at $25 \mathrm{keV}$ which was produced via the ${ }^{7} \mathrm{Li}(p, n)^{7} \mathrm{Be}$ reaction using a proton beam of $1912 \mathrm{keV}$ [21]. The number of produced ${ }^{61} \mathrm{Fe}$ atoms was measured by $\gamma$-spectrometry using a pair of Glover detectors. 118 single events and 17 coincidences were observed in the course of these measurements. The neutron capture cross section at stellar energies $(k T=25 \mathrm{keV})$ was calculated to be

$$
\langle\sigma\rangle=(5.8 \pm 1.7 \text { syst } \pm 0.8 \text { stat }) \text { mbarn }
$$

applying the new ${ }^{60} \mathrm{Fe}$ half-life [15]. All details of the experiment are described in [19].

\subsection{Preparation of ${ }^{60} \mathrm{Fe}$ and ${ }^{26} \mathrm{Al}$ standard material for AMS}

Accelerator Mass Spectrometry (AMS) as - in most cases - a relative measurement technique requires the availability of the respective reference material. The concentration of the radionuclide in the reference material is in many cases (for instance ${ }^{26} \mathrm{Al}$ and ${ }^{60} \mathrm{Fe}$ ) certified using radiation measurement techniques. In these cases, the absolute AMS measurement value, e.g. the isotopic ratio, is directly related to the half-life. For instance for ${ }^{60} \mathrm{Fe}$ the isotope ratios of previous standards had to be scaled by a factor of $\sim 1.7$ due to new half-life value. It is, therefore, very important that wellcharacterized standard materials are available in the required amounts.

We obtained from the stock solution used for the halflife measurement a series of ${ }^{60} \mathrm{Fe}$-standards, consisting of $\mathrm{Fe}_{2} \mathrm{O}_{3}$ in three isotopic ratios $\left({ }^{60} \mathrm{Fe} /{ }^{\text {stable }} \mathrm{Fe}\right): \sim 1 \times 10^{-12}$, $\sim 1 \times 10^{-10}$ and $\sim 1 \times 10^{-8}$. The material was prepared by measuring the initial ${ }^{60} \mathrm{Fe}$ concentration in the stock solution with ICP-MS and subsequent stepwise dilution with stable 


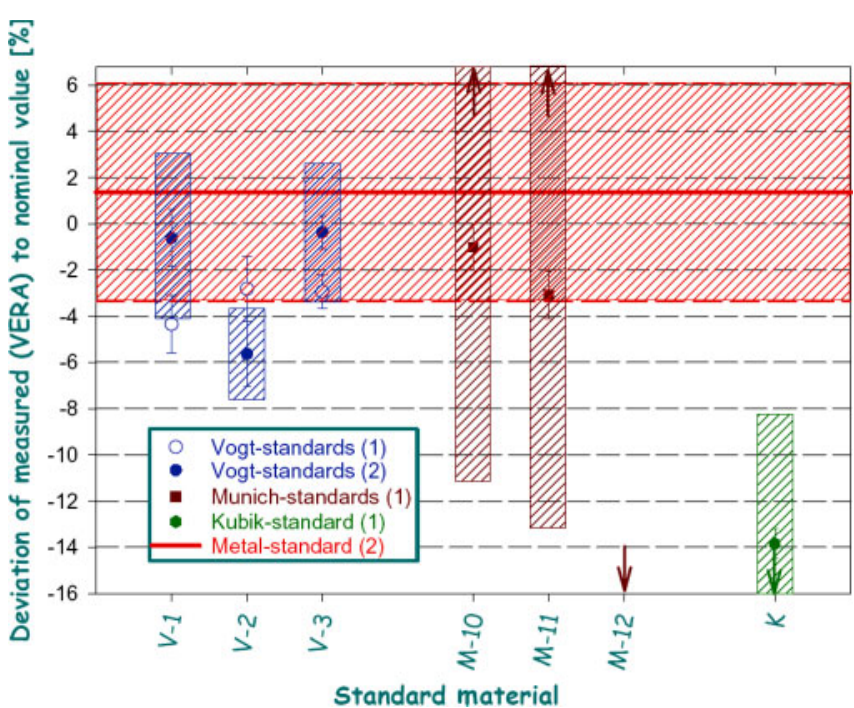

Fig. 1. Comparison of several standard materials; figure taken from Ref. [25].

iron. The final characterization by Accelerator mass spectrometry is currently underway.

Considering the high importance of a well-characterized and certified reference material in AMS, it is surprising, that up to now such standard reference materials can seldom be commercially purchased, and if at all, they are extremely expensive, like in the case of ${ }^{26} \mathrm{Al}$. Moreover, results of the first international inter-laboratory comparison showed discrepancies of the respective in-house reference samples of up to $10 \%$ [23]. As can be seen in Fig. 1, also the standard materials themselves can differ widely from one laboratory to another [25]. Obviously, certified material is rare and not available to every laboratory, the quantity of the provided material is not sufficient for distributing it to all interested laboratories and the preparation of the final samples is not carried out in consistent procedures. Therefore, there is a strong need to prepare a sufficient amount of ${ }^{26} \mathrm{Al}$ reference material with high accuracy, which can be provided to all interested laboratories world-wide.

We used samples from a proton-irradiated copper beam dump for the isolation of ${ }^{26} \mathrm{Al}$ sufficient for producing AMS reference material. Details of the chemical separation can be found in $[6,7]$.

The ${ }^{26} \mathrm{Al}$, extracted from the $\mathrm{Cu}$ matrix, was diluted to $25 \mathrm{~mL} 1 \mathrm{M} \mathrm{HCl}$. From this stock solution a sample was sent to Physikalisch-Technische Bundesanstalt (PTB) Braunschweig in order to perform a certified absolute $\gamma$ measurement.

Two subsamples of the delivered ${ }^{26} \mathrm{Al}$ stock solution, with a mass of $3.95 \mathrm{~g}$ each, were transferred to cylindrical vials with $25 \mathrm{~mm}$ diameter. The ${ }^{26} \mathrm{Al}$ activity in each subsample was determined by measuring the characteristic $\gamma$-radiation in an absolute efficiency calibrated with a high purity germanium (HPGe) spectrometer. The measuring period for both subsamples was $285 \mathrm{~h}$. The HPGe spectrometer is a secondary-standard measuring device calibrated by activity standards from primary standardization of the PTB. The absolute activity of the sample was deduced taken into account coincidence-summing correction. These measurements yield a specific activity of the stock solution
Table 1. Measured isotopic ratios for the ${ }^{26} \mathrm{Al}$ AMS standard.

\begin{tabular}{lcccccc}
\hline No. & $\begin{array}{c}I\left[10^{-11}\right] \\
\text { ETHZ }\end{array}$ & $\delta$ & $\begin{array}{c}I\left[10^{-11}\right] \\
\text { VERA }\end{array}$ & $\delta$ & $I\left[10^{-11}\right]$ & Date \\
$\gamma$ & & -1.2 & 10.12 & 19 Apr 2007 \\
1 & - & - & 9.99 & -10.8 & 10.12 & 19 Apr 2007 \\
2 & - & - & 10.2 & +0.8 & 10.12 & 26 Sep 2007 \\
3 & 11.05 & +9.2 & - & - & 10.12 & 26 Sep 2007 \\
4 & 11.03 & +8.9 & - & - & &
\end{tabular}

of $(0.448 \pm 0.014) \mathrm{Bq} / \mathrm{g}$. The uncertainty stated is the expanded uncertainty obtained according to the "ISO Guide to the Expression of Uncertainty in Measurement" by multiplying the combined standard uncertainty by the coverage factor $k=2$, i.e. it corresponds approximately to a coverage probability of $95 \%$.

A $4 \mathrm{~mL}$ aliquot of the solution was transferred into a suitable vial and used as $\gamma$-calibration source for further ${ }^{26} \mathrm{Al}$ samples in a high purity germanium well detector.

Four different AMS samples were prepared each from the stock solution for a subsequent comparison at several AMS facilities. In Table 1 the results of the measurements performed at VERA (Vienna) and ETHZ (Zurich) are shown in comparison to the calculated isotopic ratio from the $\gamma$-ray spectrometric measurement.

The data in Table 1 show that ETHZ overestimates the value from the $\gamma$-measurement by about $8-9 \%$ which was expected already from earlier measurements (see Fig. 1).

From that material, approximately $240 \mathrm{~g} \mathrm{Al}_{2} \mathrm{O}_{3}$ (corresponding to $130 \mathrm{~g} \mathrm{Al}$ ), samples can be provided to interested users, based on an isotope ratio of about $10^{-10}$. In total, the amount will be sufficient to prepare up to 260000 AMS samples.

\subsection{Separation of ${ }^{207} \mathrm{Bi}$ from irradiated lead}

Proton-irradiated lead samples from the SINQ target represent a unique and valuable pool for the retrieval of rare exotic radionuclides with higher atomic numbers. Due to the long irradiation time - usually two years - and the high proton intensity, high activity concentrations can be expected. First works on the determination of the radionuclide inventory distribution within such a SINQ target are currently ongoing.

One of the radionuclides, useful as calibration source for $\gamma$-spectrometry, is ${ }^{207} \mathrm{Bi}$. With its relatively long half-life of $31.5 \mathrm{yr}$ and three $\gamma$-lines up to $1800 \mathrm{keV}$, it is best-suited for several applications requiring high-energy calibration points in $\gamma$-spectroscopy. Moreover, from lead as target material, the production of stable $\mathrm{Bi}$ is not favored, giving the possibility to produce even no-carrier-added (n.c.a.) samples.

In previous works, we determined the radionuclide content of samples from the SINQ target 4 [26]. In general, SINQ targets consist of a bundle of lead rods clad with SS 316L or Zircaloy tubes assembled as a cannelloni setup. Target 4 was in use from $20^{\text {th }}$ March 2000 till $23^{\text {rd }}$ December 2001 and was irradiated with an integrated beam of $10.03 \mathrm{Ah}$. We have found ${ }^{207} \mathrm{Bi}$ activities of up to $30 \mathrm{MBq} / \mathrm{g}$, making this exploitation project very promising.

For the preparation of a $200 \mathrm{kBq}$ calibration source, around $10 \mathrm{mg}$ lead were dissolved in $10 \mathrm{~mL} 7 \mathrm{M} \mathrm{HNO}_{3}$ and 

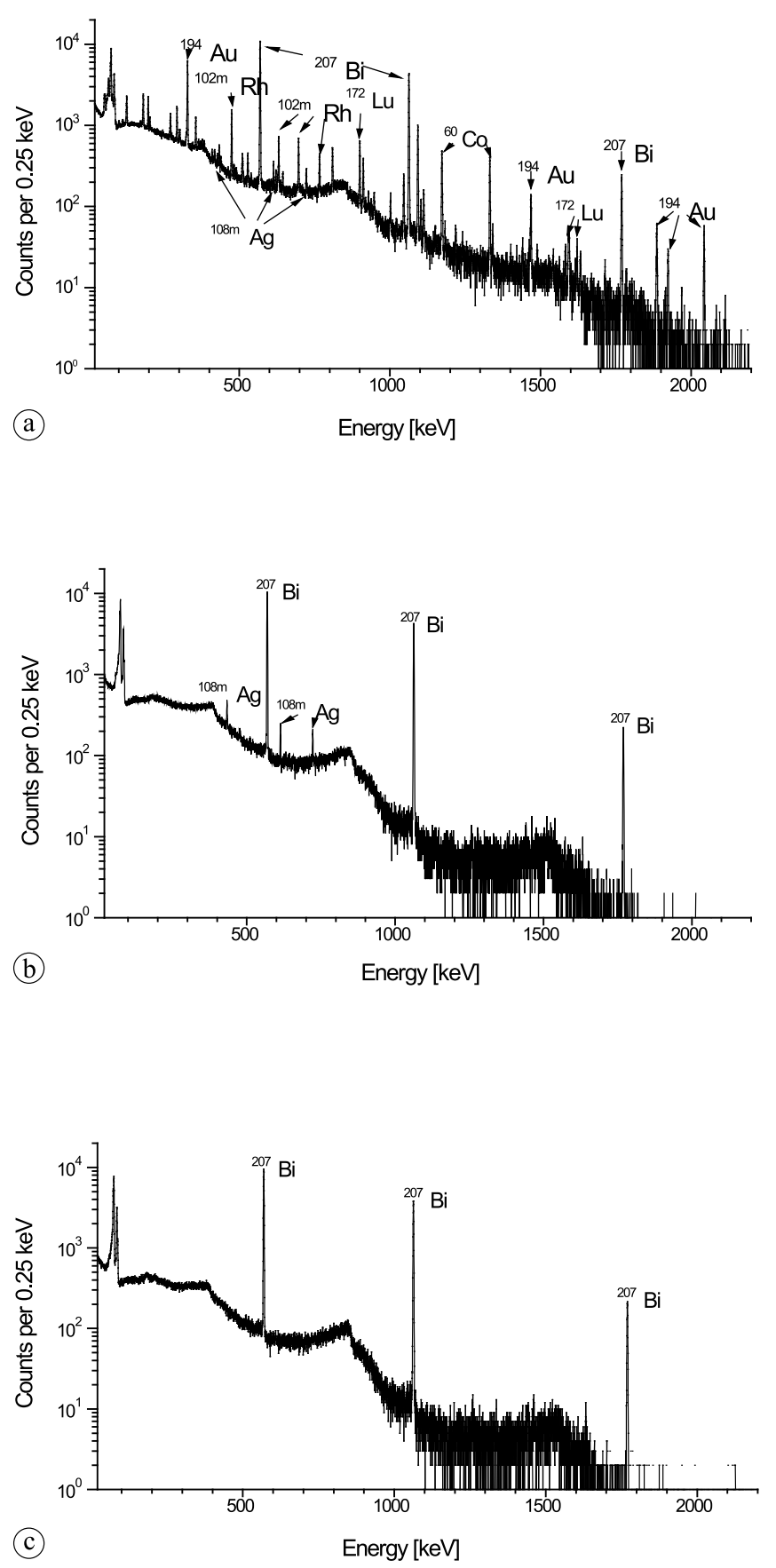

Fig. 2. $\gamma$-ray spectra of the ${ }^{207} \mathrm{Bi}$ sample: (a) without chemical treatment, (b) after first separation, (c) final product.

evaporated, till a precipitation of $\mathrm{Pb}\left(\mathrm{NO}_{3}\right)_{2}$ occurred. The over standing solution was measured using a HPGe detector (ORTEC) (Fig. 2a). The given $\gamma$-spectra were obtained using a HPGe spectrometer with a bulletized crystal in coaxial assembly with a diameter of $53 \mathrm{~mm}$ and a length of $44 \mathrm{~mm}$ resulting in a relative full-energy peak efficiency of $21.8 \%$. The pre-amplifier of the detector is connected to a Canberra ${ }^{\circledR}$ acquisition interface module based counting system and the Canberra ${ }^{\circledR}$ Genie 2000 data acquisition and analysis PC-program suite. The full width at half-maximum of the counting setup is $0.80 \mathrm{keV}$ at $122 \mathrm{keV}$ and $1.73 \mathrm{keV}$ at $1332 \mathrm{keV}$, respectively.

The supernate solution was decanted and evaporated to dryness. The residue was dissolved in $3 \mathrm{M} \mathrm{HNO}_{3}$ and passed through a lead-specific ion exchange column (Eichrom) in order to remove traces of lead. The eluate was again evaporated and the activity dissolved in $1 \mathrm{M} \mathrm{HNO}_{3}$. This solution was loaded onto a cation exchange column (DOWEX $50 \times$ 8, 200-400 mesh, $\mathrm{H}^{+}$form). Afterwards, the column was washed with $10 \mathrm{~mL} 1 \mathrm{M} \mathrm{HNO}_{3}$. Then, the Bi-fraction could be eluted with $6 \mathrm{~mL} 0.4 \mathrm{M} \mathrm{HCl}$ and was measured in the same geometry (Fig. 2b).

After this treatment, the ${ }^{207} \mathrm{Bi}$ fraction showed only a slight contamination with ${ }^{108 \mathrm{~m}} \mathrm{Ag}$. In order to remove this impurity, in a final purification step $1 \mathrm{mg}$ La was added and concentrated ammonia solution was used to precipitate the hydroxide. Whereas ${ }^{207} \mathrm{Bi}$ was found completely in the precipitate, silver stayed as ammonia complex in solution. To get rid of the lanthanum, the precipitate was dissolved in $1 \mathrm{M}$ $\mathrm{HNO}_{3}$ once more and the purification procedure using the ion exchange column was repeated as described before.

After the final purification step, silver was completely removed as can be seen in Fig. 2c. The final sample contains $\sim 260 \mathrm{kBq}$. With the availability of more sample material from SINQ targets in the near future, we can now think about the establishment of a routine production of such rare and valuable radionuclides.

Further works aimed to separate the long-lived ${ }^{182} \mathrm{Hf}$ as well as lanthanides like the $\alpha$-emitting ${ }^{148} \mathrm{Gd}$ and ${ }^{146} \mathrm{Sm}$ are currently ongoing. These isotopes are not detectable by non-destructive radiation measurement techniques, but the presence of lighter lanthanides like ${ }^{172} \mathrm{Lu}$ in the $\gamma$-spectrum (Fig. 2a) makes their presence very likely.

Extended model studies are necessary to develop suitable chemical separation techniques, especially for the lanthanide separation.

\subsection{Separation of ${ }^{44} \mathrm{Ti}$ and other radionuclides from stainless steel [8]}

Massive stars end their life as a supernova, where part of the stellar material is ejected and the remaining core collapses as a neutron star or a black hole. Supernova are some of the most energetic explosions in the Universe, providing an excellent laboratory for nuclear physics and astrophysics research. During core collapse supernova, the ejected core matter is totally decomposed into protons, neutrons and $\alpha$ particles due to the high temperatures. The development of the super nova shock wave region and the connected cooling down leads to the so called explosive nucleosynthesis of heavy elements. ${ }^{44} \mathrm{Ti}$ is produced in a region where the temperature drops down to $0.25 \mathrm{GK}$ and the $\alpha$-rich freeze-out takes place.

${ }^{44} \mathrm{Ti}\left(T_{1 / 2}=60.4 \mathrm{yr}\right)$ can be observed in the cosmos, due to its decay product ${ }^{44} \mathrm{Sc}$ with a half-life of about $4 \mathrm{~h}$ and a well-measureable $\gamma$-line of $1157 \mathrm{keV}$, which makes this isotope, similar to the long-lived ${ }^{26} \mathrm{Al}\left(E_{\gamma}=1808 \mathrm{keV}\right)$, extremely interesting for studying the processes in the universe [27]. Due to its relatively short half-life the observations of ${ }^{44} \mathrm{Ti}$ in the universe yield information about the conditions during and shortly after the core collapse. The interpretation of this signal depends not only on our knowledge about the production mechanism but also on all possible destruction paths of ${ }^{44} \mathrm{Ti}$, as they are the radioactive decay and radiation or particle induced reactions. Among others, the reaction ${ }^{44} \operatorname{Ti}(\alpha, p)^{47} \mathrm{~V}$ is one of the 
most significant processes to destroy ${ }^{44} \mathrm{Ti}$ in the cosmic environment.

The main contributor to the $\gamma$-ray dose in our source samples - proton irradiated ferritic or martensitic steel specimen - is, after a cooling time of around $10 \mathrm{yr},{ }^{44} \mathrm{Ti}$. Due to the comparable low dose rate, making the handling relatively easy, and the high activity concentration of ${ }^{44} \mathrm{Ti}$, these samples count as the most prospective ones for the preparation of ${ }^{44} \mathrm{Ti}$ samples. Besides this main radioactive component, also considerable amounts of ${ }^{53} \mathrm{Mn}$ and ${ }^{26} \mathrm{Al}$ were found. Therefore, a subsequent chemical separation procedure was developed and successfully applied. At the moment, a ${ }^{44} \mathrm{Ti}$ source with more than $100 \mathrm{MBq}$ is available; the preparation of the other two samples ${ }^{26} \mathrm{Al}$ and ${ }^{53} \mathrm{Mn}$ will follow soon. The chemical separation procedures, based on liquid-liquid extraction, precipitation and ion exchange are described in detail in [9].

A first experiment with ${ }^{44} \mathrm{Ti}$ was successfully performed in fall 2012 at CERN-ISOLDE studying the ${ }^{44} \mathrm{Ti}(\alpha, p)^{47} \mathrm{~V}$ reaction in inverse kinematics by producing a radioactive beam of ${ }^{44} \mathrm{Ti}$ and bombarding a 200 mbar helium target. The data analysis is currently going on. The use of inverse kinematics reactions provides the possibility to separate ${ }^{44} \mathrm{Ti}$ from other stable $\mathrm{Ti}$ isotopes present in the sample, thus suppressing unwanted side reactions. Moreover, the detection of the reaction products is improved due to the higher kinetic energy of the reaction products. However, an investigation of the ${ }^{44} \mathrm{Ti}(\alpha, p)^{47} \mathrm{~V}$ reaction using a ${ }^{44} \mathrm{Ti}$ target and an $\alpha$-particle beam is also planned (at HZDR, Germany). For these investigations, ${ }^{44} \mathrm{Ti}$ targets implanted at CERN ISOLDE have to be manufactured.

\section{$3.7^{10} \mathrm{Be}$ from proton-irradiated graphite [30]}

Another "hot topic" in nuclear data is the half-life of ${ }^{10} \mathrm{Be}$, where the literature values differ from $1.34 \times 10^{6} \mathrm{yr}$ to $1.51 \times 10^{6} \mathrm{yr}$ [31]. As much as possible additional determinations of the ${ }^{10} \mathrm{Be}$ half-life are, therefore, needed to obtain a reliable value. One possibility for a re-measurement of the ${ }^{10} \mathrm{Be}$ half-life is the use of Liquid Scintillation Counting (LSC) for the determination of the activity and MC-ICPMS for measuring the number of atoms. An experiment dedicated to the re-measurement of the half-life of ${ }^{10} \mathrm{Be}$ is foreseen at PSI in collaboration with PTB Braunschweig.

${ }^{10} \mathrm{Be}$ represents - moreover - a proxy of a halo nucleus. These halo nuclei consist of a compact core nucleus in accordance with the classical picture of a nucleus plus one or several weakly bound nucleons orbiting the inner core with relatively large distances. From charge radii measurements in comparison to the neighboring non-halo isotopes the effect of the halo-neutrons on the inner core can be studied. For that, an intense ${ }^{10} \mathrm{Be}$ beam is necessary. The development of such a beam with ${ }^{10} \mathrm{Be}$ from PSI is foreseen at INFN Catania [5].

For the separation of ${ }^{10} \mathrm{Be}$ in amounts up to several $10 \mu \mathrm{g}$ we used irradiated graphite stemming from the "Target E" at PSI. This installation is a rotating carbon wheel which produces muons for several particle physics experiments [33]. Moreover, it serves as a "beam shaper" for the SINQ. Up to now we extracted about $80 \mu \mathrm{g}$ or $4.8 \times 10^{18}$ atoms of ${ }^{10} \mathrm{Be}$. Details of the chemical processing are given in [30].

\subsection{Preparation of a ${ }^{63} \mathrm{Ni}$ target for $n \_T O F[12]$}

${ }^{63} \mathrm{Ni}$, with a half-life of $100.1 \mathrm{yr}$ [34] represents another example of long-lived radionuclides, where neutron capture competes with radioactive decay. ${ }^{63} \mathrm{Ni}$ is produced in the weak s-process taking place in massive stars during two different burning stages: i) during He Core burning (at temperatures of $k T=26 \mathrm{keV}$ ), where neutron densities are too small to bypass the decay channel and ${ }^{63} \mathrm{Ni}$ entirely decays to ${ }^{63} \mathrm{Cu}$, and ii) during $\mathrm{C}$ shell burning $(k T=91 \mathrm{keV})$ where subsequent neutron capture on ${ }^{63} \mathrm{Ni}$ becomes the dominant reaction. Network calculations showed that e.g. the final ${ }^{63 / 65} \mathrm{Cu}$ abundances strongly depend on the ${ }^{63} \mathrm{Ni}(n, \gamma)$ cross section [35]. However, no experimental data are available above thermal neutron energies and all estimates for stellar environments are based on either calculations or extrapolations of the thermal cross section. Therefore, the n_TOF collaboration measured the neutron capture cross section of ${ }^{63} \mathrm{Ni}$ at the n_TOF facility from thermal up to energies of hundreds of $\mathrm{keV}$.

The material for the experiment originated from two metallic nickel targets: one with $347 \mathrm{mg}$ and the second with $661 \mathrm{mg}$. Both consist of enriched ${ }^{62} \mathrm{Ni}(98 \%)$ and were produced for Mössbauer spectroscopy at TU Munich by irradiation in high flux reactors about $30 \mathrm{yr}$ ago to a final content of around $11 \%{ }^{63} \mathrm{Ni}$. Since the decay product ${ }^{63} \mathrm{Cu}$ disturbs the neutron capture measurements due to intense neutron resonances, chemical separation of the copper was required.

The Ni metal was dissolved in $7 \mathrm{M} \mathrm{HNO}_{3}$, evaporated to dryness and again dissolved in $1 \mathrm{M} \mathrm{HCl}$. From this solution, $\mathrm{CuS}$ was precipitated by adding gaseous $\mathrm{H}_{2} \mathrm{~S}$. In model experiments with natural $\mathrm{Ni}$ it could be demonstrated using inductively coupled plasma optical emission spectroscopy (ICP-OES), that a decontamination factor of 2000 for $\mathrm{Cu}$ could be obtained. The precipitate was removed and

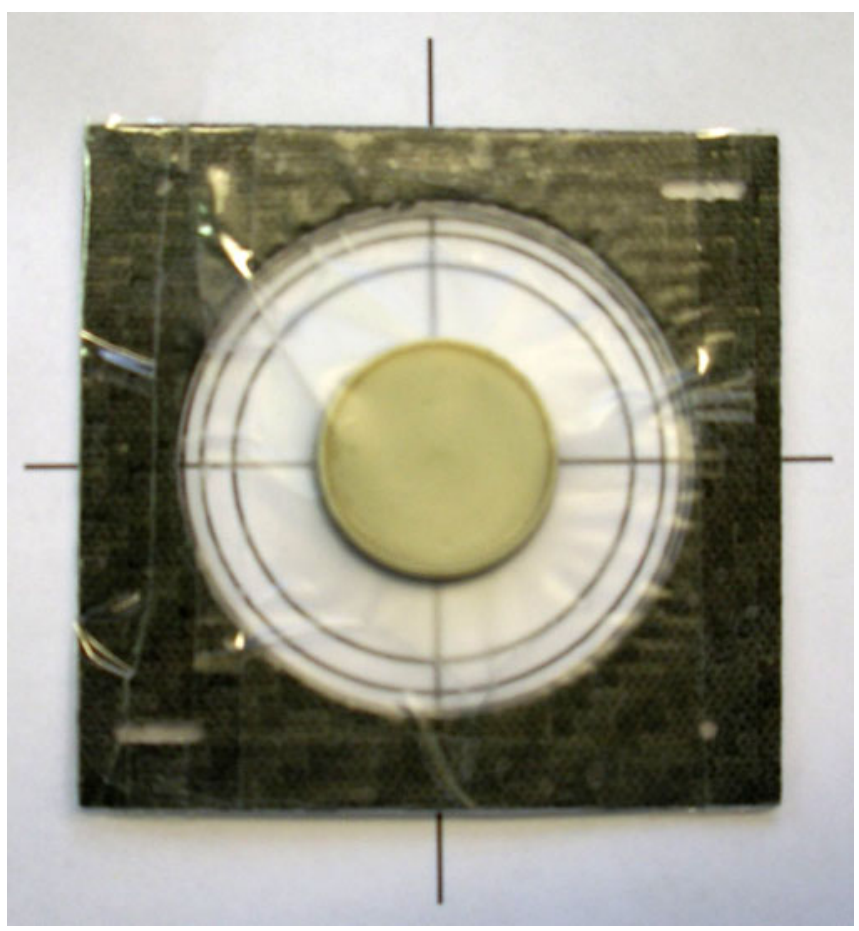

Fig. 3. Photo of the final ${ }^{62 / 63} \mathrm{Ni}$ target used at $\mathrm{n} \_\mathrm{TOF}$. 
$\mathrm{Ni}(\mathrm{OH})_{2}$ was precipitated from the remaining solution by adding $5 \mathrm{M} \mathrm{NaOH}$. The hydroxide was dried at $80^{\circ} \mathrm{C}$ and afterwards calcinated at $800{ }^{\circ} \mathrm{C}$ to produce $\mathrm{NiO}$. We obtained a total amount of $1147 \mathrm{mg} \mathrm{NiO}$, corresponding to a chemical yield of $91 \%$. The material was packed into a PEEK capsule, as can be seen in Fig. 3.

\section{Conclusion and outlook}

In the frame of our ERAWAST initiative within the last six years, impressive progresses could be achieved concerning the separation of long-lived exotic radionuclides from accelerator waste. First successful experiments with ${ }^{60} \mathrm{Fe},{ }^{44} \mathrm{Ti}$ and other exotic radionuclides could be performed. During the second ERAWAST workshop, a user community had been established which will in the near future carry out a number of exciting scientific experiments in the field of nuclear astrophysics and basics nuclear physics research. Some examples are:

1. The re-measurement of the ${ }^{60} \mathrm{Fe}$ half-life as a round robin test with the University of Vienna and PSI to confirm the new value of $2.62 \times 10^{6} \mathrm{yr}$.

2. The determination of the neutron capture cross section of ${ }^{60} \mathrm{Fe}$ at thermal energies in collaboration with the Universities of Frankfurt and Mainz.

3. The measurement of the reaction ${ }^{44} \mathrm{Ti}(\alpha, p)^{47} \mathrm{~V}$ at TRI$\mathrm{UMF}$ Vancouver with a radioactive ${ }^{44} \mathrm{Ti}$ ion beam in inverse kinematics.

4. The measurement of the ${ }^{44} \mathrm{Ti}(\alpha, p)^{47} \mathrm{~V}$ reaction using a fixed ${ }^{44} \mathrm{Ti}$ target at HZDR Dresden Rossendorf.

5. The re-measurement of the half-lives of ${ }^{10} \mathrm{Be}$ and ${ }^{63} \mathrm{Ni}$ in collaboration with PTB Braunschweig.

6. The re-measurement of the ${ }^{53} \mathrm{Mn}$ half-life and the neutron capture cross section.

7. The study of the reactions ${ }^{7} \mathrm{Be}(n, \alpha) \alpha$ and $\left.{ }^{7} \mathrm{Be}(n, p)\right)^{7} \mathrm{Li}$ with a ${ }^{7} \mathrm{Be}$ target at SARAF in Israel and at n_TOF CERN.

We intend to develop chemical separation devices applicable to remote-controlled processing in hotcells with larger amounts of materials in order to provide the desired isotopes in the required amounts and purity. Particularly valuable for us in this regard is the recently established collaboration with the n_TOF community.

Acknowledgment. We would like to thank Viktor Boutellier for the hotcell work, Peter Kubik for AMS measurements and Silvia Köchli for ICP-OES measurements. Special thanks go to A. Wallner for remeasuring the ${ }^{26} \mathrm{Al}$ samples and very useful improvements of the manuscript.

\section{References}

1. The MYRRHA facility: http://myrrha.sckcen.be/.

2. The SNS facility: http://neutrons.ornl.gov/.

3. The ESS facility: http://ess-scandinavia.eu/ESS.

4. ERAWAST I, November 2006, Villigen, Switzerland, http://lch web.psi.ch/webcontent/research/radwaste/workshop/index.html.

5. ERAWAST II, August 2011, Villigen, Switzerland, http://lch.web. psi.ch/webcontent/research/radwaste/Erawast2/index.html.

6. Schumann, D., Neuhausen, J.: Accelerator waste as a source for exotic radionuclides. J. Phys. G: Nucl. Part. Phys. 35, 014046 (2008).
7. Schumann, D., Neuhausen, J., Eikenberg, J., Ruthi, M., Wohlmuther, M., Kubik, P. W., Synal, H. A., Alfimov, V., Korschinek, G., Rugel, G., Faestermann, T.: Radiochemical analysis of a copper beam dump irradiated with high-energetic protons. Radiochim. Acta 97, 123 (2009).

8. Dai, Y., Bauer, G.: Status of the first SINQ irradiation program, STIP I. J. Nucl. Mater. 296, 43 (2001).

9. Dressler, R., Ayranov, M., Bemmerer, D., Bunka, M., Dai, Y., Lederer, C., Fallis, J., Murphy, A. St, J., Pignatari, M., Schumann, D., Stora, T., Stowasser, T., Thielemann, F.-K., and Woods, P. J.: ${ }^{44} \mathrm{Ti}$, ${ }^{26} \mathrm{Al}$ and ${ }^{53} \mathrm{Mn}$ samples for nuclear astrophysics: the needs, the possibilities and the sources. J. Phys. G: Nucl. Part. Phys. 39, 105201 (2012)

10. Schumann, D. Ayranov, M., Stowasser, T., Gialanella, L., di Leva, A., Romano, M., Schuermann, D.: Radiochemical separation of ${ }^{7} \mathrm{Be}$ from the cooling water of the neutron spallation source SINQ at PSI. Radiochim. Acta 101, DOI: 10.1524/ ract.2013.2078 (2013).

11. Wagner, W., Yong Dai, Glasbrenner, H., Aebersold, H.-U.: Materials irradiation facilities at the high-power Swiss proton accelerator complex. J. Nucl. Mater. 361, 274 (2007).

12. Lederer, C., Massimi, C., Altstadt, S., Andrzejewski, J., Audouin, L., Barbagallo, M., Bécares, V., Bečvář, F., Belloni, F., Berthoumieux, E., Billowes, J., Boccone, V., Bosnar, D., Brugger, M., Calviani, M., Calviño, F., Cano-Ott, D., Carrapiço, C., Cerutti, F., Chiaveri, E., Chin, M. Colonna, N., Cortés, G., CortésGiraldo, M. A., Diakaki, M., Domingo-Pardo, C., Duran, I., Dressler, R., Dzysiuk, N., Eleftheriadis, C., Ferrari, A., Fraval, K., Ganesan, S., García, A. R., Giubrone, G., Gómez-Hornillos, M. B., Gonçalves, I. F., González-Romero, E., Griesmayer, E., Guerrero, C., Gunsing, F., Gurusamy, P., Jenkins, D. G., Jericha, E., Kadi, Y., Käppeler, F., Karadimos, D., Kivel, N., Koehler, P., Kokkoris, M., Korschinek, G., Krtièka, M., Kroll, J., Langer, C., Leeb, H., Leong, L. S., Losito, R., Manousos, A., Marganiec, J., Martínez, T., Mastinu, P. F., Mastromarco, M., Meaze, M., Mendoza, E., Mengoni, A., Milazzo, P. M., Mingrone, F., Mirea, M., Mondelaers, W., Paradela, C., Pavlik, A., Perkowski, J., Pignatari, M., Plompen, A., Praena, J., Quesada, J. M., Rauscher, T., Reifarth, R., Riego, A., Roman, F., Rubbia, C., Sarmento, R., Schillebeeckx, P., Schmidt, S., Schumann, D., Tagliente, G., Tain, J. L., Tarrío, D., Tassan-Got, L., Tsinganis, A., Valenta, S., Vannini, G., Variale, V., Vaz, P., Ventura, A. Versaci, R., Vermeulen, M. J., Vlachoudis, V., Vlastou, R., Wallner, A., Ware, T., Weigand, M., Weiß, C., Wright, T. J., Žugec, P.: Neutron capture cross section of unstable ${ }^{63} \mathrm{Ni}$ : implications for stellar nucleosynthesis. Phys. Rev. Lett. 110, 022501 (2013).

13. Käppeler, F., Gallino, R., Bisterzo, S., Wako Aoki: The s process: Nuclear physics, stellar models, and observations. Rev. Mod. Phys. 83, 157 (2011).

14. Käppeler, F.: Reaction cross sections for the $s, r$, and $p$ process. Prog. Part. Nucl. Phys. 66, 390 (2011).

15. Rugel, G., Faestermann, T., Knie, K., Korschinek, G., Poutivtsev, M., Schumann, D., Kivel, N., Gunther-Leopold, I., Weinreich, R., Wohlmuther, M.: New measurement of the Fe-60 half-life. Phys. Rev. Lett. 103, 072502 (2009).

16. Kutschera, W., Billquist, P. J., Frekers, D., Henning, W., Jensen, K. J., Ma Xiuzeng, Pardo, R., Paul, M., Rehm, K. E., Smither, R. K., Yntema, J. L., Mausner, L. F.: Half-life of ${ }^{60}$ Fe. Nucl. Instrum. Methods Phys. Res. Sect. B 5, 430 (1984).

17. Kivel, N., Schumann, D., Günther-Leopold, I.: Quantification of ${ }^{60} \mathrm{Fe}$ atoms by MC-ICP-MS for the redetermination of the halflife. Anal. Bioanal. Chem. 405(9), 2965-2972 (2012).

18. Williams, J. P.: The astrophysical environment of the solar birthplace. Contemp. Phys. 51, 381 (2010).

19. Uberseder, E., Reifarth, R., Schumann, D., Dillmann, I., Domingo Pardo, C., Görres, J., Heil, M., Käppeler, F., Marganiec, J., Neuhausen, J., Pignatari, M., Voss, F., Walter, S., Wiescher, M.: Measurement of the ${ }^{60} \mathrm{Fe}(n, \gamma){ }^{61} \mathrm{Fe}$ cross section at stellar temperatures. Phys. Rev. Lett. 102, 151101 (2009).

20. Schumann, D., Neuhausen, J., Dillmann, I., Domingo Pardo, C., Käppeler, F., Marganiec, J., Voss, F., Walter, S., Heil, M., Reifarth, R., Goerres, J., Uberseder, E., Wiescher, M., Pignatari, M.: Preparation of a Fe-60 target for nuclear astrophysics experiments. Nucl. Instrum. Methods Phys. Res. Sect. A 613, 347 (2010). 
21. Beer, H., Käppeler, F.: Neutron capture cross sections on ${ }^{138} \mathrm{Ba}$, ${ }^{140,142} \mathrm{Ce},{ }^{175,176} \mathrm{Lu}$, and ${ }^{181} \mathrm{Ta}$ at $30 \mathrm{keV}$ : Prerequisite for investigation of the ${ }^{176} \mathrm{Lu}$ cosmic clock. Phys. Rev. C 21, 534 (1980).

22. Heil, M., Käppeler, F., Uberseder, E., Gallino, R., Bisterzo, S., Pignatari, M.: Stellar $(n, \gamma)$ cross sections for $\mathrm{Br}$ and $\mathrm{Rb}$ : Matching the weak and main s-process components. Phys. Rev. C 77, 015808 (2008)

23. Merchel, S., Bremser, W.: First international ${ }^{26} \mathrm{Al}$ interlaboratory comparison - Part I. Nucl. Instrum. Methods Phys. Res. Sect. B 223, 393 (2004).

24. Merchel, S., Bremser, W.: First international ${ }^{26} \mathrm{Al}$ interlaboratory comparison - Part II. Nucl. Instrum. Methods Phys. Res. Sect. B 229, 217 (2005)

25. Wallner, A., Ikeda, Y., Kutschera, W., Priller, A.,, Steier, P., Vonach, H., Wild, E.: Precision and accuracy of ${ }^{26} \mathrm{Al}$ measurements with VERA. Nucl. Instrum. Methods B 172, 382 (2000); Wallner, A.: PhD thesis, Univ. of Vienna (2000).

26. Lorenz, T., Schumann, D., Dai, Y.: Analysis of long-lived radionuclides produced by proton irradiation in lead targets - first results. Radiochim. Acta, accepted (2013).

27. Iyudin, A. F., Diehl, R., Bloemen, H., Hermsen, W., Lichti, G. G., Morris, D., Ryan, J., Schoenfelder, V., Steinle, H., Varendorff, M., de Vries, C., Winkler, C.: COMPTEL observations of Ti-44 gamma-ray line emission from CAS A. Astron. Astrophys. 284, L1 (1994).

28. Lebrun, F., Cordier, B., Iyudin, A.: ${ }^{44}$ Ti lines in the integral core programme data. (Gimenez, A., Reglero, V., Winkler, C., eds.) Proc. of the $4^{\text {th }}$ INTEGRAL Workshop Exploring the Gamma Ray Universe, Alicante, ESA SP 459 (2001), pp. 509-513.

29. Renaud, M., Lebrun, F., Terrier, R., Prantzos, N., Decourchelle, A., Ballet, J.: The study of young galactic supernovae through ${ }^{44} \mathrm{Ti}$ gamma-ray line emission with INTEGRAL, 35th COSPAR Scientific Assembly (2004), p. 2694.
30. Schumann, D., Neuhausen, J., Horn, S., Kubik, P. W., GüntherLeopold, I.: Radiochemical separation and analytical determination of ${ }^{10} \mathrm{Be}$ from proton-irradiated graphite targets. Radiochim. Acta 96, 31 (2008).

31. Middleton, R., Brown, L., Dezfouly-Arjomandy, B., Klein, J.: On ${ }^{10} \mathrm{Be}$ standards and the half-life of ${ }^{10} \mathrm{Be}$. Nucl. Instrum. Methods Phys. Res. Sect. B 82, 399 (1993).

32. Korschinek, G., Bergmaier, A., Faestermann, T., Gerstmann, U. C., Knie, K., Rugel, G., Wallner, A., Dillmann, I., Dollinger, G., Lierse von Gostomski, Ch., Kossert, K., Maiti, M., Poutivtsev, M., Remmert, A.: A new value for the half-life of ${ }^{10} \mathrm{Be}$ by heavyion elastic recoil detection and liquid scintillation counting. Nucl. Instrum. Methods Phys. Res. Sect. B 268, 187 (2010).

33. http://ltp.web.psi.ch/.

34. Collè, R., Zimmermann, B. E., Cassette, P., Laureano-Perez, L.: ${ }^{63} \mathrm{Ni}$, its half-life and standardization: Revisited, Appl. Rad. Isotopes 66, 60 (2008).

35. Pignatari, M., Gallino, R., Heil, M., Wiescher, M., Käppeler, F., Herwig, F., Bisterzo, S.: The weak s-process in massive stars and its dependence on the neutron capture cross sections. The Astrophys. J. 710, 1557 (2010).

36. Renaud, M., Vink, J., Decourchelle, A., Lebrun, F., den Hartog, P. R., Terrier, R., Couvreur, C., Knödlseder, J., Martin, P., Prantzos, N., Bykov, A. M., Bloemen, H.: The signature of ${ }^{44} \mathrm{Ti}$ in cassiopeia as revealed by ibis/isgri on integral. The Astrophys. J. 647, L41 (2006).

37. The, L.-S., Clayton, D., Diehl, R., Hartmann, D. H., Iyudin, A. F., Leising, M. D., Meyer, B. S., Motizuki, Y., Schönfelder, V.: Are ${ }^{44} \mathrm{Ti}$-producing supernovae exceptional? Astron. Astrophys. 450, 1037 (2006).

38. Schumann, D., Ayranov, M.: Preparation of ${ }^{60} \mathrm{Fe},{ }^{7} \mathrm{Be},{ }^{44} \mathrm{Ti}$ and others for nuclear physics experiments. J. Phys. Conf. Series 202, 012034 (2010). 